\title{
Perhitungan Metode Fuzzy Sugeno Dan Antropometri Dalam Memprediksi Status Gizi Indeks Massa Tubuh
}

\section{Calculation of Fuzzy Sugeno and Anthropometric Methods In Predicting Nutritional Status of Body Mass Index}

\author{
Dinur Syahputra ${ }^{1) *}$, Muhathir ${ }^{2)}$ \\ ${ }^{1)}$ Magister Teknik Informatika, Fasilkom TI, Universitas Sumatera Utara, Indonesia \\ ${ }^{2)}$ Prodi Informatika, Fakultas Teknik Universitas Medan Area, Indonesia
}

*Coresponding Email: didinsyahdin231@gmail.com

\begin{abstract}
Abstrak
Antropometri merupakan ilmu yang mempelajari berbagai ukuran tubuh manusia. Dalam bidang ilmu gizi digunakan untuk menilai status gizi. Metode yang digunakan adalah fuzzy sugeno, yaitu aturan yang direpresentasikan dalam bentuk IF-THEN dengan output berupa konstanta untuk melakukan perhitungan terhadap status gizi indeks massa tubuh. Dalam hal memprediksi status gizi indeks massa tubuh dilakukanlah perhitungan dengan menggunakan metode fuzzy sugeno dan antropometri.Prosedur untuk mendapatkan status gizi yaitu dengan menyesuaikan nilai gizi yang telah diperoleh ke dalam fungsi keanggotaan himpunan fuzzy pada variabel nilai gizi. Himpunan fuzzy nilai gizi diperoleh berdasarkan klasifikasi pada Indeks Massa Tubuh (IMT), yang direpresentasikan menggunakan himpunan fuzzy.
\end{abstract}

Kata Kunci: Antropometri, Fuzzy Sugeno,Status Gizi

\begin{abstract}
Anthropometry is the study of the various sizes of the human body. The method used is fuzzy sugeno, the rule represented in the form of IF-THEN with the output of a constant to perform the calculation of the nutritional status of the body mass index. In terms of prediction of nutritional status of mass index done by using method of fuzzy sugeno and antropometri.Prosedur to get nutritional status by using nutrition variable. The fuzzy set of Nutritional Value generated on the Body Mass Index (IMT), which is represented by the fuzzy set.
\end{abstract}

\section{Keywords : Anthropometry, Fuzzy Sugeno, Nutritional Status}

How to Cite: Syahputra, D. Muhathir. (2018). Perhitungan Metode Fuzzy Sugeno Dan Antropometri Dalam Memprediksi Status Gizi Indeks Massa Tubuh. JITE (Journal Of Informatics And Telecommunication Engineering). Vol (2). No (1): 16-22 


\section{PENDAHULUAN}

Menurut [3], Indonesia mengalami beban ganda masalah gizi yaitu masih banyak masyarakat yang kekurangan gizi, tetapi di sisi lain terjadi gizi lebih. Kurang gizi maupun gizi lebih disebabkan karena tidak adanya keseimbangan antara asupan zat gizi dengan kebutuhan zat gizi dalam tubuh. Hal ini tidak terlepas dari makanan yang dikonsumsi setiap harinya.

Masalah kekurangan dan kelebihan gizi pada orang dewasa (usia 18 tahun keatas) merupakan masalah penting, karena selain mempunyai risiko penyakit penyakit tertentu, juga dapat mempengaruhi produktifitas kerja. Oleh karena itu, pemantauan keadaan tersebut perlu dilakukan secara berkesinambungan. Salah satu cara adalah dengan mempertahankan berat badan yang ideal atau normal.

Logika fuzzy juga memiliki kemampuan untuk menyimpulkan hasil yang valid (ketepatan dalam pengukuran) dari basis aturan yang berisi pengetahuan yang diekstraksi berdasarkanpengetahuan dan pengalaman pakar yang menjadikan popularitas logika fuzzy meningkat [4][6].

Fuzzy metode sugeno merupakan metode inferensi fuzzy untuk aturan yang direpresentasikan dalam bentuk IF THEN, dimana output (konsekuen) sistem tidak berupa himpunan fuzzy, melainkan berupa konstanta atau persamaan linear [1]. Metode Sugeno dipakai karena dalam proses perhitungan status gizi selama ini masih dilakukan secara antropometri, sehingga masih adanya tingkat kesalahan dalam perhitungan tersebut. Saat ini teknologi informasi semakin berkembang dalam aspek apapun, salah satunya dalam aspek perhitungan dengan data yang diambil dari antropometri. Dalam hal ini perhitungan dapat menggunakan Metode Sugeno, yang dapat mengantisipasi kesalahan dengan aturan - aturan yang akan di inputkan.

\section{Metode Sugeno}

Fuzzy metode sugeno merupakan metode inferensi fuzzy untuk aturan yang direpresentasikan dalam bentuk IF THEN, dimana output (konsekuen) sistem tidak berupa himpunan fuzzy, melainkan berupa konstanta atau persamaan linear [1]. Metode sugeno ini merupakan metode fuzzy yang telah terbukti efektif ketika berhadapan dengan sistem nonlinear yang kompleks, yang sangat sulit untuk analisis dan sintesis [5].

Pada metode Sugeno, setiap output (konsekuen) terbentuk dari aturan IFTHEN tidak berupa himpunan fuzzy, melainkan konstanta atau persamaan linear. Terdapat dua model fuzzy metode sugeno, yaitu : 


\section{Model Fuzzy Sugeno Orde-Nol}

Secara umum bentuk fuzzy sugeno adalah sebgai berikut :

IF ( $x 1$ is $A 1) A N D(x 2$ is $A Z) A N D$...

$A N D(x n$ is $A n)$ THEN $\angle=k$

Dengan Ai adalah himpunan fuzzyke-i sebagai anteseden dan $\mathrm{k}$ adalah suatu konstanta (tegas) sebagai konsekuen.

\section{Model Fuzzy Sugeno Orde-Satu}

Secara umum bentuk fuzzy sugeno adalah sebgai berikut :

IF $(x 1$ is A1)AND( $x 2$ is Az)AND ...AND (xn is An) $\mathrm{k}$

THEN $z=p 1 * x 1+\cdots+p n * x n+\varphi$

Dengan Ai adalah himpunan fuzzy kei sebagai anteseden dan pi adalah suatu konstanta (tegas) ke-i dan q juga merupakan konstanta dalam konsekuen.

Model Sugeno merupakan usaha untuk mengembangkan pendekatan sistematis untuk membangun aturan samar atau fuzzy dari himpunan data masukan dan keluaran (Jang, dkk, 1997). Aturan fuzzy- Sugeno biasanya didefinisikan sebagai:

JIKA $\mathrm{x}$ adalah A DAN y adalah B MAKA $z=f(x, y)$

Di mana A dan B adalah himpunan fuzzy pada anteseden, dan $\mathrm{z}=\mathrm{f}(\mathrm{x}, \mathrm{y})$ merupakan fungsi crisp konsekuen.

Untuk memperoleh output diperlukan 4 tahapan, diantaranya:

\section{Pembentukan himpunan fuzzy}

Pada metode Fuzzy Sugeno, baik variabel input maupun variabel output dibagi menjadi satu atau lebih himpunan fuzzy.

\section{Aplikasi fungsi implikasi (aturan)}

Menurut Cox (1994) metode Fuzzy-

Sugeno terdiri dari dua jenis, yaitu:

\section{Model Fuzzy-Sugeno orde nol}

Secara umum bentuknya adalah:

JIKA ( $\mathrm{x}_{1}$ adalah $\left.\mathrm{A}_{1}\right) \circ\left(\mathrm{x}_{2}\right.$ adalah $\left.\mathrm{A}_{2}\right) \circ$ $\left(\mathrm{x}_{3}\right.$ adalah $\left.\mathrm{A}_{3}\right) \circ \ldots \circ\left(\mathrm{x}_{\mathrm{i}}\right.$ adalah $\left.\mathrm{A}_{\mathrm{i}}\right)$ MAKA $\mathrm{z}=$

\section{Model Fuzzy-Sugeno orde satu}

Secara umum bentuknya adalah:

JIKA $\left(\mathrm{x}_{1}\right.$ adalah $\left.\mathrm{A}_{1}\right) \circ\left(\mathrm{x}_{2}\right.$ adalah $\left.\mathrm{A}_{2}\right) \circ \ldots$ $\circ\left(\mathrm{x}_{\mathrm{i}}\right.$ adalah $\left.\mathrm{A}_{\mathrm{i}}\right)$ MAKA z $=p_{1} * \chi_{1}+\cdots+p_{i} * \chi_{i}+q$

Dengan A1 adalah himpunan Fuzzy ke-i sebagai antiseden, $p_{i}$ konstanta tegas ke-i dan $q$ konstanta pada konsekuen.

\section{Komposisi aturan}

Apabila sistem terdiri dari beberapa aturan, maka inferensi diperoleh dari kumpulan dan korelasi antar aturan. Metode yang digunakan dalam melakukan inferensi sistem fuzzy ini adalah Metode Max (Maximum) yaitu menghitung hasil dari $\sum_{r=1}^{R} \propto_{r} z_{r}$ dengan $\mathrm{R}$ banyaknya rule, $u_{r}$ fire strength ke-r.

\section{Metode Max (Maximum)}

Pada metode ini, solusi himpunan fuzzy diperoleh dengan cara mengambil 
nilai maksimum aturan, kemudian memantau status gizi orang dewasa, menggunakan nilai tersebut untuk khususnya yang berkaitan dengan memodifikasi daerah fuzzy dan kekurangan dan kelebihan berat badan. mengaplikasikannya ke output dengan Penggunaan IMT hanya berlaku menggunakan operator $O R$ (gabungan). untuk orang dewasa berumur lebih dari 18 Jika semua proporsi telah dievaluasi, maka tahun dan tidak dapat diterapkan pada output akan berisi himpunan fuzzy yang bayi, anak, remaja, ibu hamil, dan merefleksikan kontribusi dari tiap-tiap olahragawan. Pada atlet, postur tubuh proporsi. Secara umum dapat dituliskan:

$$
\mu\left(x_{i}\right)=\max \left\{\mu_{s f}\left(x_{i}\right), \mu_{k f}\left(x_{i}\right)\right\}
$$

Dengan:

$\mu_{s f}\left(x_{i}\right)=$ nilai keanggotaan solusi fuzzy sampai aturan ke-i

$\mu_{k f} \quad\left(x_{i}\right)=$ nilai keanggotaan konsekuen fuzzy aturan ke-i

\section{Penegasan (defuzzyfication)}

Masukan dari proses penegasan adalah suatu himpunan fuzzy yang diperoleh dari komposisi aturan-aturan fuzzy, sedangkan output yang dihasilkan merupakan suatu bilangan real yang tegas. Jika diberikan suatu himpunan fuzzy dalam range tertentu, maka dapat diambil suatu nilai tegas tertentu sebagai output.

Untuk proses defuzzifikasi, metode sugeno menggunakan Weight Average (WA) dengan rumus sebagai berikut :

$$
z=\frac{u_{1} z_{1}+u_{2} z_{2}+\ldots \ldots+u_{m} z_{m}}{u_{1}+u_{2}+\ldots \ldots+u_{m}}
$$

\section{Indeks Massa Tubuh}

$$
\text { Indeks Massa Tubuh }
$$

merupakan alat yang sederhana untuk yang ideal berbeda antara setiap jenis cabang olah raga. Misalnya postur tubuh yang ideal bagi atlet petinju atau binaraga, sangat berbeda pada atlet senam atau renang. Atlet tinju dan binaraga membutuhkan massa tubuh yang besar, otot dan tulang yang kuat untuk berlatih atau bertanding. Berbeda pada atlet senam atau renang, yang membutuhkan massa tubuh yang tidak terlalu besar, tetapi tetap membutuhkan otot dan tulang yang kuat dan lentur. Untuk kondisi ini diperlukan pengukuran yang khusus, seperti pengukuran tebal lemak untuk menilai apakah massa tubuh yang besar pada atlet tersebut terdiri dari otot atau lemak.

Rumus perhitungan IMT adalah sebagai berikut:

$$
\mathrm{IMT}=\frac{\text { Berat badan }(\mathrm{kg})}{\text { Tingg1 badan }(\mathrm{m}) \times \text { Tingg badan }(\mathrm{m})}
$$

Tabel 1. Kategori Ambang Batas IMT untuk Indonesia

\begin{tabular}{|l|l|}
\hline Status Gizi & IMT $\left(\mathbf{k g} / \mathbf{m}^{\mathbf{2}}\right)$ \\
\hline Kurus Sekali & $<17.0$ \\
\hline Kurus & $17.0-18.4$ \\
\hline Normal & $18.5-25.0$ \\
\hline Gemuk & $25.1-27.0$ \\
\hline Gemuk Sekali & $>27.0$ \\
\hline \multicolumn{2}{|c|}{$[2]$}
\end{tabular}




\section{METODE PENELITIAN}

Pada metode penelitian ini digunakan metode fuzzy sugeno dan antropometri untuk mendapatkan hasil dalam memprediksi status gizi indeks massa tubuh. Penelitian ini dilakukan berdasarkan penelitian sebelumnya yang menggunakan metode tsukamoto dan antropometri untuk mendapatkan status gizi seimbang. Oleh karena itu penulis akan melakukan pengujian perhitungan metode sugeno dengan data manual yang diambil dari antropometri dalam penelitian. Dengan menggunakan perhitungan Metode Sugeno akan menghasilkan fungsi keanggotaan representasi linear dengan didukung data dari antropometri.

Pada penelitian ini menggunakan perhitungan metode dengan data manual yang diambil dari antropometri dengan cara menganalisis data terlebih dahulu, kemudian setelah data terkumpul maka akan dilakukan pengambilan data dengan sampel berdasarkan usia 18 tahun ke atas. Setelah itu data di uji menggunakan metode sugeno untuk menentukan fungsi keanggotaan dari sampel yang telah diambil, kemudian data tersebut memperoleh hasil yang diambil dari antropometri.

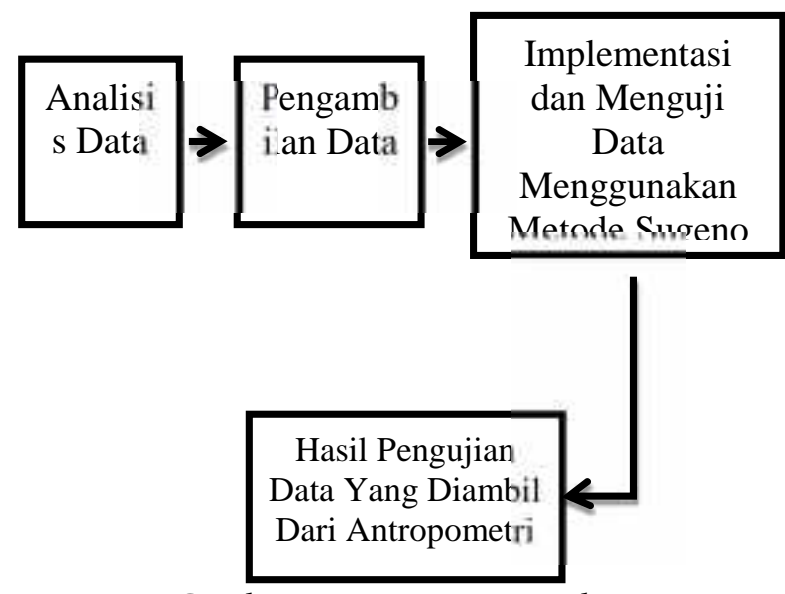

Gambar 1. Rancangan Penelitian

\section{HASIL DAN PEMBAHASAN}

Setelah rule terbentuk, maka dilakukanlah evaluasi rule unuk melihat hasil yang didapat dari metode fuzzy sugeno dan antropometri. Dan setelah evaluasi rule dilakukan, maka selanjutnya melakukan evaluasi tingkat akurasi yang diambil dari data antropometri.

Tabel 2. Hasil Evaluasi Rule

\begin{tabular}{|l|l|l|l|l|}
\hline \multirow{2}{*}{ Data } & \multicolumn{2}{|c|}{ Status Pasien } & \multicolumn{2}{|l}{} \\
\cline { 2 - 4 } & $\begin{array}{l}\text { Berat } \\
\text { Badan } \\
(\text { Kg })\end{array}$ & $\begin{array}{l}\text { Tinggi } \\
\text { Badan } \\
(\mathrm{M})\end{array}$ & Antropometri & Sugeno \\
\hline 01 & 52 & 1.5 & 23.11111 & 22.96296 \\
\hline 02 & 48 & 1.65 & 17.63085 & 16.18468 \\
\hline 03 & 62 & 1.49 & 27.92667 & 28.50242 \\
04 & 68 & 1.68 & 24.09297 & 24.47728 \\
\hline 05 & 62 & 1.65 & 22.77319 & 22.19013 \\
\hline 06 & 62 & 1.58 & 24.83576 & 26.02907 \\
\hline 07 & 55 & 1.52 & 23.8054 & 23.87879 \\
\hline 08 & 55 & 1.73 & 18.37683 & 18.37972 \\
\hline 09 & 62 & 1.65 & 22.77319 & 22.19013 \\
\hline 10 & 70 & 1.57 & 28.39872 & 28.59137 \\
\hline
\end{tabular}




\begin{tabular}{|l|l|l|l|l|}
\hline 11 & 59 & 1.52 & 25.5367 & 25.66305 \\
\hline 12 & 82 & 1.71 & 28.04282 & 23.86462 \\
\hline 13 & 82 & 1.68 & 29.05329 & 24.47728 \\
\hline 14 & 54 & 1.58 & 21.63115 & 21.4822 \\
\hline 15 & 72 & 1.65 & 26.44628 & 24.99803 \\
\hline 16 & 60 & 1.63 & 22.58271 & 22.82816 \\
\hline 17 & 58 & 1.6 & 22.65625 & 23.55765 \\
\hline 18 & 35 & 1.45 & 16.64685 & 17.77778 \\
\hline 19 & 55 & 1.53 & 23.49524 & 23.59596 \\
\hline 20 & 40 & 1.56 & 16.43655 & 16.54361 \\
\hline 21 & 50 & 1.55 & 20.81165 & 19.85308 \\
\hline 22 & 57 & 1.56 & 23.42209 & 23.93988 \\
\hline 23 & 100 & 1.5 & 44.44444 & 31.11111 \\
\hline
\end{tabular}

\begin{tabular}{|c|c|c|c|c|c|}
$\mathbf{1 9}$ & 55 & 1.53 & Normal & Normal & Benar \\
\hline $\mathbf{2 0}$ & 40 & 1.56 & $\begin{array}{c}\text { Kurus } \\
\text { Sekali }\end{array}$ & $\begin{array}{c}\text { Kurus } \\
\text { Sekali }\end{array}$ & Benar \\
\hline $\mathbf{2 1}$ & 50 & 1.55 & Normal & Normal & Benar \\
\hline $\mathbf{2 2}$ & 57 & 1.56 & Normal & Normal & Benar \\
\hline $\mathbf{2 3}$ & 100 & 1.5 & $\begin{array}{c}\text { Gemuk } \\
\text { Sekali }\end{array}$ & $\begin{array}{c}\text { Gemuk } \\
\text { Sekali }\end{array}$ & Benar \\
\hline
\end{tabular}

Menentukan status gizi pada antropometri adalah berat badan dan tinggi badan. Sedangkan dalam metode Fuzzy Sugeno yaitu melalui proses pembentukan himpunan fuzzy, aplikasi

Tabel 3. Evaluasi Tingkat Akurasi

\begin{tabular}{|c|c|c|c|c|c|}
\hline \multirow[b]{2}{*}{ Data } & \multicolumn{2}{|c|}{ Status Pasien } & \multirow{2}{*}{ 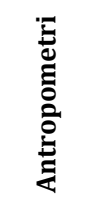 } & \multirow{2}{*}{$\begin{array}{c}\text { Fuzzy } \\
\text { Sugeno }\end{array}$} & \multirow{2}{*}{ 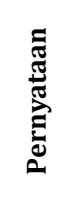 } \\
\hline & $\begin{array}{c}\text { Berat } \\
\text { Badan } \\
(\mathrm{Kg})\end{array}$ & $\begin{array}{l}\text { Tinggi } \\
\text { Badan } \\
\text { (M) }\end{array}$ & & & \\
\hline 01 & 52 & 1.5 & Normal & Normal & Benar \\
\hline 02 & 48 & 1.65 & Kurus & $\begin{array}{l}\text { Kurus } \\
\text { Sekali }\end{array}$ & Salah \\
\hline 03 & 62 & 1.49 & $\begin{array}{l}\text { Gemuk } \\
\text { Sekali }\end{array}$ & $\begin{array}{l}\text { Gemuk } \\
\text { Sekali }\end{array}$ & Benar \\
\hline 04 & 68 & 1.68 & Normal & Normal & Benar \\
\hline 05 & 62 & 1.65 & Normal & Normal & Benar \\
\hline 06 & 62 & 1.58 & Normal & Gemuk & Salah \\
\hline 07 & 55 & 1.52 & Normal & Normal & Benar \\
\hline 08 & 55 & 1.73 & Kurus & Kurus & Benar \\
\hline 09 & 62 & 1.65 & Normal & Normal & Benar \\
\hline 10 & 70 & 1.57 & $\begin{array}{l}\text { Gemuk } \\
\text { Sekali }\end{array}$ & $\begin{array}{l}\text { Gemuk } \\
\text { Sekali }\end{array}$ & Benar \\
\hline 11 & 59 & 1.52 & Gemuk & Gemuk & Benar \\
\hline 12 & 82 & 1.71 & $\begin{array}{l}\text { Gemuk } \\
\text { Sekali }\end{array}$ & Normal & Salah \\
\hline 13 & 82 & 1.68 & $\begin{array}{l}\text { Gemuk } \\
\text { Sekali }\end{array}$ & Normal & Salah \\
\hline 14 & 54 & 1.58 & Normal & Normal & Benar \\
\hline 15 & 72 & 1.65 & Gemuk & Normal & Salah \\
\hline 16 & 60 & 1.63 & Normal & Normal & Benar \\
\hline 17 & 58 & 1.6 & Normal & Normal & Benar \\
\hline 18 & 35 & 1.45 & $\begin{array}{l}\text { Kurus } \\
\text { Sekali }\end{array}$ & Kurus & Salah \\
\hline
\end{tabular}

fungsi implikasi, operasi himpunan fuzzy dan proses penegasan (defuzzifikasi),maka tingkat akurasi dalam menentukan status gizi berdasarkan Indeks Massa Tubuh (IMT) yang dihasilkan dengan menggunakan Metode Fuzzy Sugeno dan Antropometri.

\section{SIMPULAN}

Metode fuzzy sugeno dapat menjadi alternatif dalam menentukan status gizi.

Adanya perhitungann nilai gizi untuk memprediksi status gizi dengan menggunakan metode fuzzy sugeno dan antropometri.

Prosedur untuk mendapatkan status gizi yaitu dengan menyesuaikan nilai gizi yang telah diperoleh ke dalam fungsi keanggotaan himpunan fuzzy pada variabel nilai gizi.

Himpunan fuzzy nilai gizi diperoleh berdasarkan klasifikasi pada Indeks Massa 
Tubuh (IMT), yang direpresentasikan menggunakan himpunan fuzzy.

\section{DAFTAR PUSTAKA}

[1] Kusumadewi, Sri. (2002). Analisis Desain Sistem Fuzzy Menggunakan Tool Box Matlab. Yogyakarta: Graha Ilmu

[2] Direktorat Gizi Masyarakat. (2003). Petunjuk Teknis Pemantauan Status Gizi Orang Dewasa dengan Indeks Massa Tubuh (IMT). Dirjen Binkesmas. Depkes RI: Jakarta.

[3] Hadi, Hamam. (2005). Beban Ganda Masalah Gizi dan Implikasinya terhadap Kebijakan Pembangunan Kesehatan Nasional

[4] Zavala, A. H., \& Nieto, O. C. (2012). Fuzzy hardware: A retrospective and analysis. IEEE Transactions on Fuzzy Systems, 20(4), 623635.

[5] Su, X., Shi, P., Wu, L., \& Song, Y. D. (2013). A novel control design on discrete-time Takagi-Sugeno fuzzy systems with timevarying delays. IEEE Transactions on Fuzzy Systems, 21(4), 655-671.

[6] Muhathir. (2015). Penentuan Kelayakan Penerbitan Paper Menggunakan Fuzzy Logic (Studi Kasus Universitas Malikussaleh). Seminar nasional teknologi rekayasa (2) 